\title{
ESR Evidence of Peroxy Radical Formation during Radiolysis of Frozen Carbohydrate Solutions
}

\author{
Andrzej Płonka, Janusz Bednarek, and Henryk Żegota \\ Institute of Applied Radiation Chemistry Technical University of Łódź, \\ 93-590 Łódź, Wróblewskiego 15, Poland
}

Z. Naturforsch. 34 b, 1525-1529 (1979); received May 21, 1979

Peroxy Radicals, Carbohydrate Solution Radiolysis

During thermal annealing of the frozen polycrystalline samples of aqueous carbohydrate (dextran, melibiose, maltose, glucose, and xylose) solutions $\gamma$-irradiated at $77 \mathrm{~K}$ the formation of peroxy radicals by addition of oxygen to the primary carbon-based radicals was observed at $190-220 \mathrm{~K}$ by the ESR method.

\section{Introduction}

Recently we have reported [1] that during the thermal annealing of cross-linked dextran gels (Sephadex G-50, Pharmacia) $\gamma$-irradiated at $77 \mathrm{~K}$ the oxygen-based radicals appeared at about $195 \mathrm{~K}$ as the paramagnetic product of radical reactions.

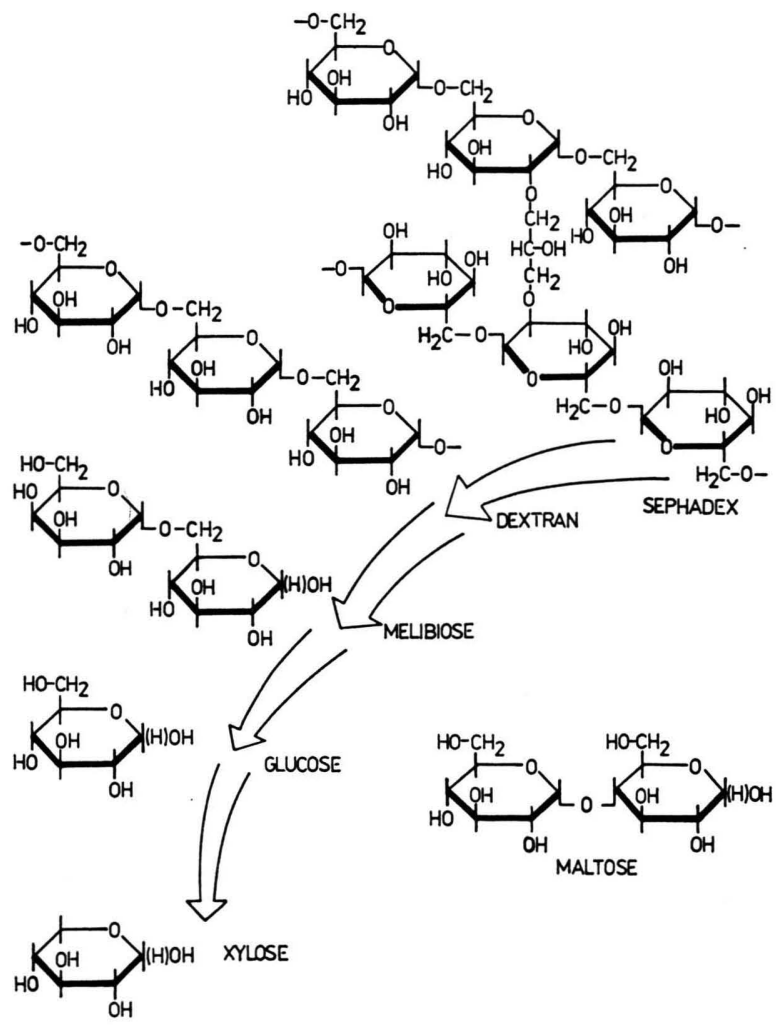

Fig. 1. The series of carbohydrates used in the present investigations.

\footnotetext{
* Reprint requests to Dr. A. Płonka. 0340-5087/79/1100-1525/\$01.00/0
}

Although it seemed easy [1] to guess the formation of such radicals from direct or indirect scission of dextran chain and/or of cross-linkage and to find some support for the intramolecular transformation of carbon based radicals into the oxygen based radicals there remained the possibility that we do observe by the ESR method the fundamental step postulated in the radiation chemistry of carbohydrates in aerated aqueous solutions [2-7]: formation of peroxy radicals by addition of oxygen to the carbon-based radicals. The experiments reported below for the series of carbohydrates depicted in Fig. 1 confirmed this fully.

\section{Experimental}

Reagent grade dextran (M. W. 70,000, Polfa, Poland), melibiose (Carl Roth OHG), maltose (POCh, Poland), glucose (POCh, Poland), and xylose (Fluka AG Switzerland) were dissolved in bidistilled water. The solutions were poured into the cylindrical containers made from thin aluminum foil (diameter $2.5 \mathrm{~mm}$, height $10 \mathrm{~mm}$ ). Before immersing these containers in liquid nitrogen there were introduced the small pieces of copper wire which enabled easy handling of the frozen samples and did not disturb the ESR measurements as checked previously. The aluminum foil was striped off under liquid nitrogen and the samples were irradiated for $1 \mathrm{~h}$, at the temperature of liquid nitrogen in the dark with Co-60 $\gamma$-rays at a dose rate of about $0.6 \mathrm{Mrad} / \mathrm{h}$. The $\gamma$-irradiated samples were transferred in the dark under liquid nitrogen, into the ESR dewar (Scanco, S-819) and the ESR spectra were recorded at $100 \mathrm{kHz}$ magnetic field modulation with an $\mathrm{X}$-band microwave spectrometer (SE-X/20, Poland) provided with $\mathrm{TE}_{104}$ cavity.

For thermal annealing the irradiated samples were transferred into a home-made variable temperature cryostat. A copper constantan thermocouple placed in contact with the sample was used to measure the temperature controlled by the flow 
rate of cold nitrogen gas. On that way a constant annealing temperature, within the range of 2 degrees, was obtained.

\section{Results}

When the samples of cross-linked dextran gel $\gamma$-irradiated in the dark at $77 \mathrm{~K}, c f$. Fig. 2, without (A) or with (B) subsequent photobleaching, were

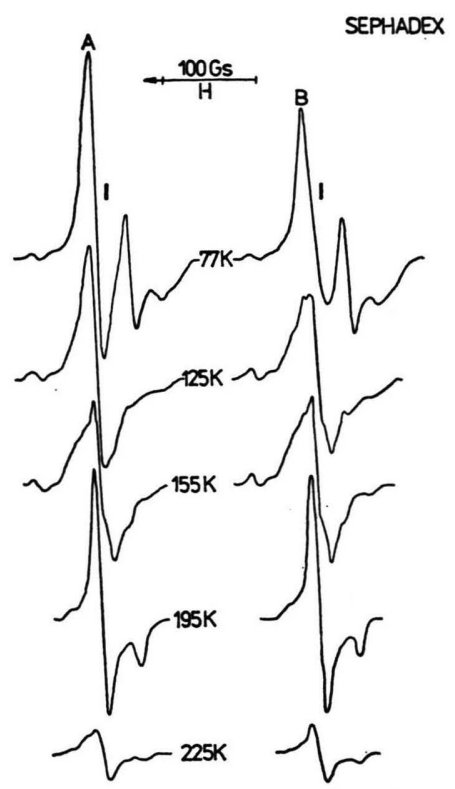

Fig. 2. X-band ESR spectra recorded at $77 \mathrm{~K} \gamma$ irradiated $(0.6 \mathrm{Mrad} / \mathrm{h}, \mathrm{l} \mathrm{h}$ at $77 \mathrm{~K}$ in the dark) crosslinked dextran gel, without (A) and with (B) subsequent photobleaching with wide band visible light, without $(77 \mathrm{~K})$ and with thermal annealing at 125 , 155,195 , and $225 \mathrm{~K}$ for $3 \mathrm{~min}$.

subjected to heat treatments for 3 min at successively higher temperature and brought back to $77 \mathrm{~K}$ for ESR recording the oxygen based radicals we are interested in appeared at $195 \mathrm{~K}$ [1].

The ESR spectra of these radicals, distinct axial symmetry with $\mathrm{g}_{1}=2.0055$ and $\mathrm{g}_{\|}=2.031$, were observed under similar experimental conditions for the polycrystalline samples of frozen solutions (17 weight per cent) of dextran annealed at $190 \mathrm{~K}$ (Fig. 3), melibiose at $210 \mathrm{~K}$ (Fig. 4), maltose at $210 \mathrm{~K}$ (Fig. 5), glucose at $220 \mathrm{~K}$ (Fig. 6), and xylose at $200 \mathrm{~K}$ (Fig. 7).

The transformation of carbon based radicals into the oxygen based radicals in the frozen aerated solutions is not complete as may be inferred from the saturation behavior of the annealed samples, cf. Fig. 8. A part of carbon based radicals remains; especially for maltose, cf. Fig. 5. In thoroughly deaerated solutions, as we have checked for glucose, there is no such transformation.

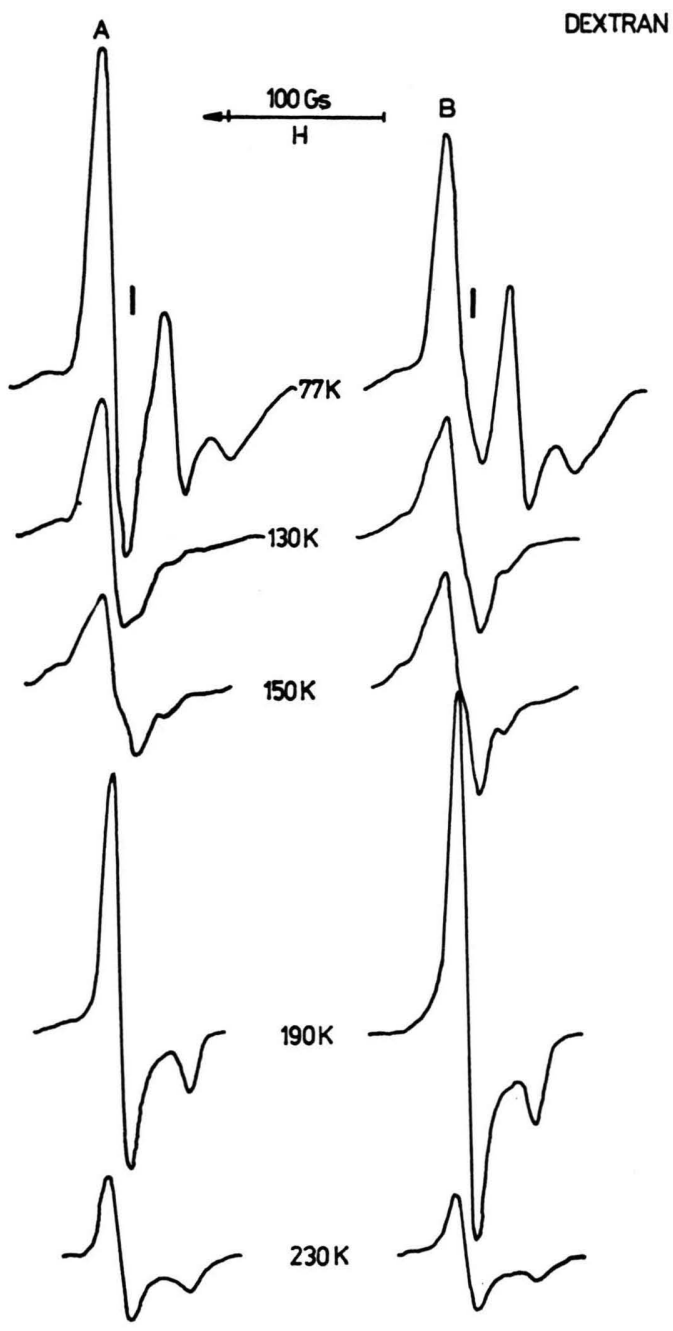

Fig. 3. The same as for 2 but for dextran.

\section{Discussion}

Quenching of the moderately concentrated aqueous solutions of carbohydrates in liquid nitrogen and subsequent $\gamma$-irradiation at that temperature leads to the stabilization of water radiolysis products (trapped electrons, hydroxyl radicals) and carbohydrate radicals in the fairly rigid matrix of polycrystalline ice [8-11], in which all reactions in- 


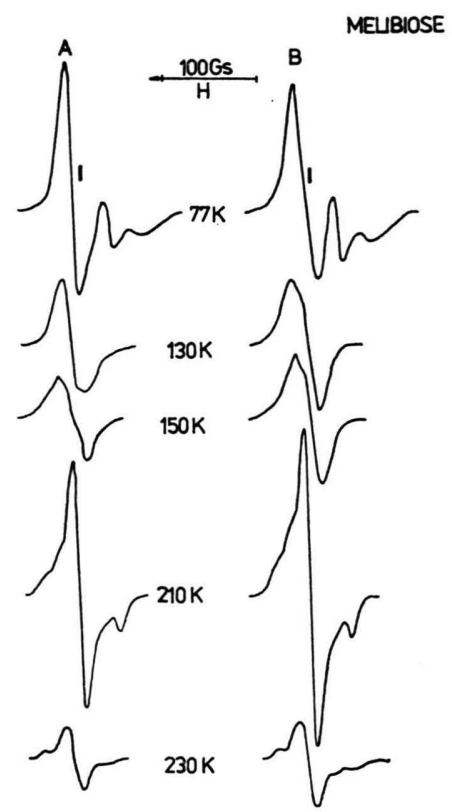

Fig. 4. The same as for 2 but for melibiose solution.

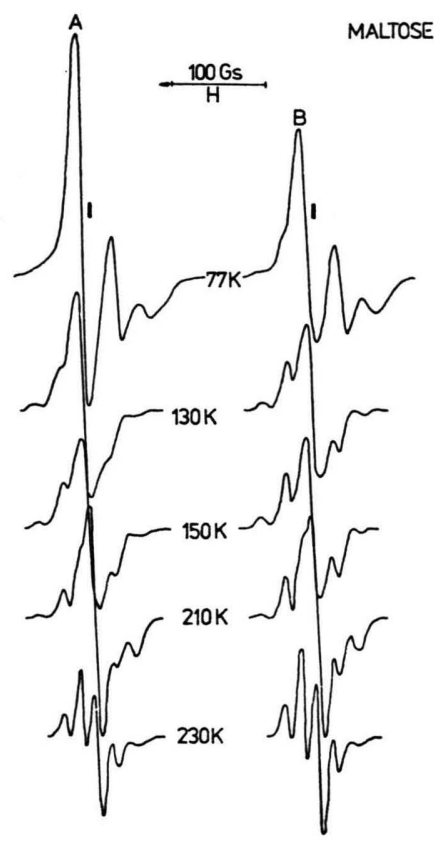

Fig. 5. The same as for 2 but for maltose solution.

volving molecular motion are effectively suppressed, $c f$. [12]. During thermal annealing of polycrystalline ice from $77 \mathrm{~K}$ to the melting point the system passe through at least three widely separated relaxation regions at $115 \pm 5,160 \pm 30$, and $230 \pm 30 \mathrm{~K}$ [13] in which due to microscopic displacement of solvent molecules the trapped species could be made mobile and/or reactive.

In the first relaxation region, as we have explored in details for cross-linked dextran gel [1], the stabilized hydroxyl radicals do decay, $c f$. [8-11, 14].

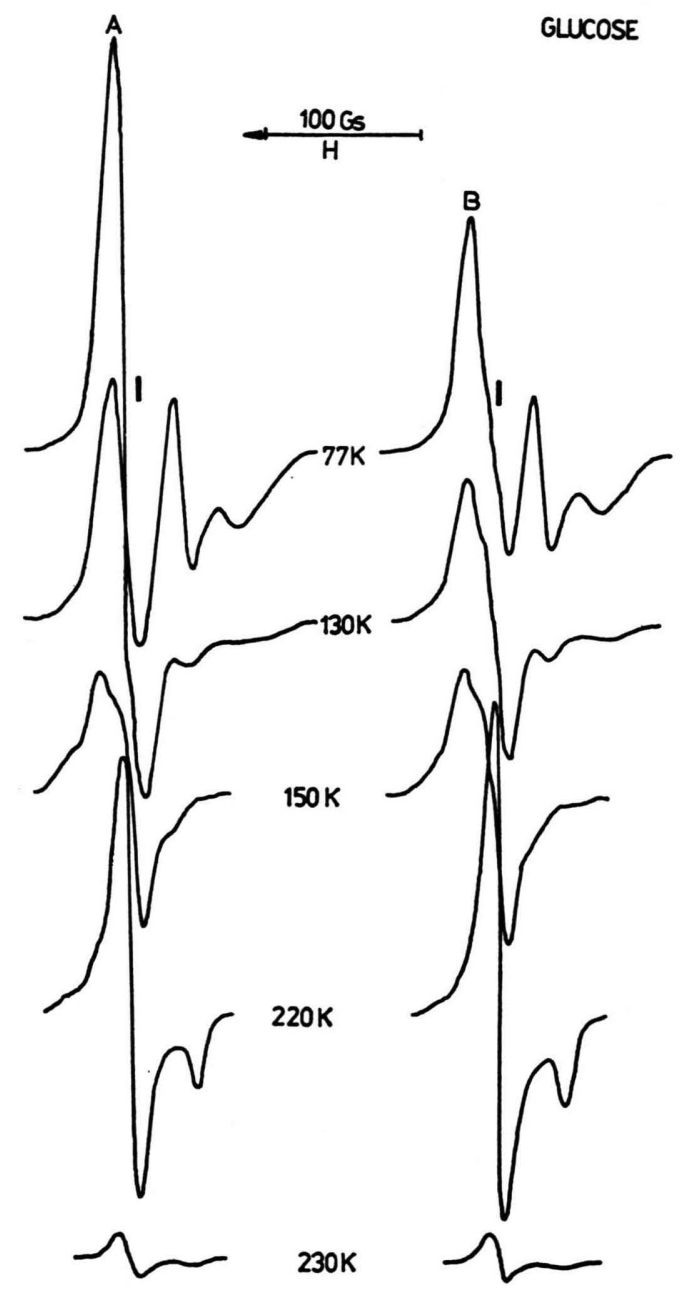

Fig. 6. The same as for 2 but for glucose solution.

The same is observed in the systems under discussion, cf. the spectra of bleached and unbleached samples of cross-linked dextran gel annealed at $125 \mathrm{~K}$ (Fig. 2), and annealed at $130 \mathrm{~K}$ dextran (Fig. 3), melibiose (Fig. 4), maltose (Fig. 5), glucose (Fig. 6), and xylose (Fig. 7).

In the second relaxation region the trapped electrons decay, $c f .[1,8-11,14]$ and spectrum $155 \mathrm{~K}$ in Fig. 2 with spectra $150 \mathrm{~K}$ in Figs. 3-7, and we are left with carbohydrate radicals. 
These carbohydrate radicals originating mainly $[2,8-11,15-17]$ from the attack of hydrogen atoms and hydroxyl radicals on carbohydrates with abstraction of carbon bound hydrogen atoms become

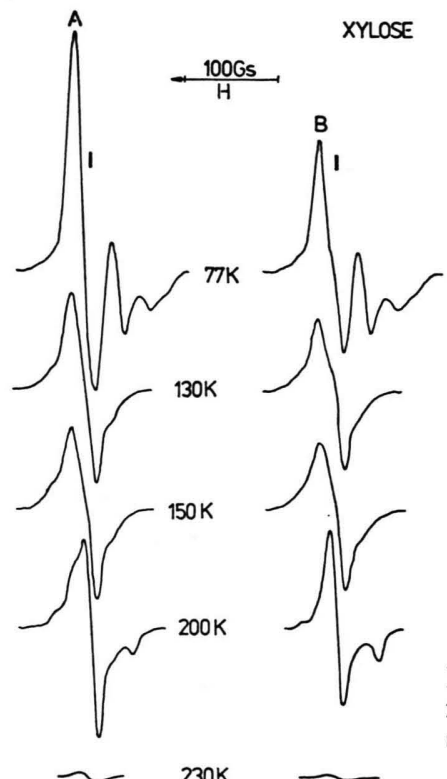

Fig. 7. The same as for 2 but for xylose solution.

reactive in the third relaxation region. In the absence of oxygen the carbon based radicals are expected to form the radiolysis products which are identical to those observed in the liquid phase [2-11]. In the liquid phase in the presence of oxygen, at concentration as low as $10^{-5} \mathrm{M}$, the radiolysis scheme involves formation of $\alpha$-hydroxylalkylperoxy radicals $[2-5]$ :

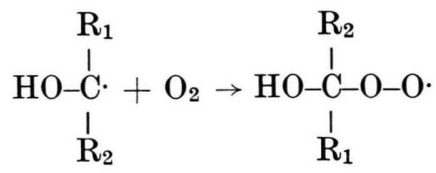

from which, as shown recently for glucose [4], all major products observed can be derived by uncatalysed decay:

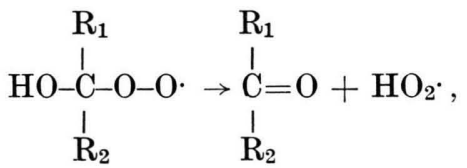

or base $\left(\mathrm{B}^{-}\right)$catalysed decay:<smiles>[R1]C([R1])(O)O[B-]C([R1])([R1])OO[I-][B]</smiles>

We are allowed to suggest that oxygen based radicals which are formed at the temperatures corresponding to the beginning of the third relaxation region are peroxy radicals. Indeed, they are not observed in deaerated samples and the main features of ESR spectra recorded for bleached or unbleached samples of cross-linked dextran gel annealed at $195 \mathrm{~K}$ (Fig. 2), annealed at $190 \mathrm{~K}$ dextran (Fig. 3), annealed at 210 melibiose (Fig. 4), annealed at 210 maltose (Fig. 5), annealed at 220 glucose (Fig. 6),

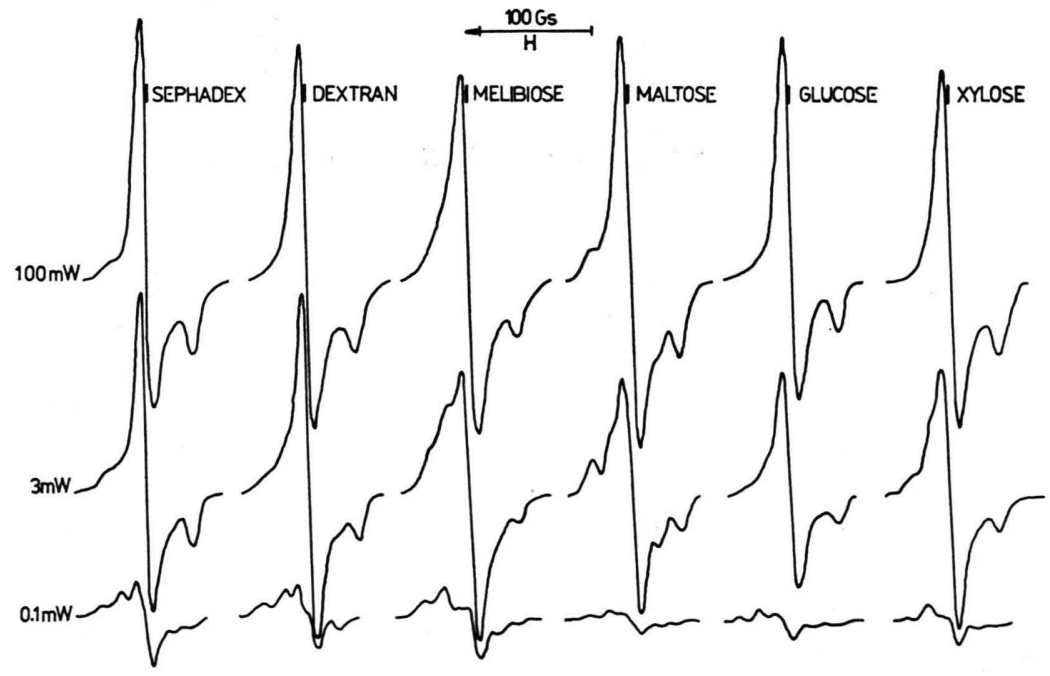

Fig. 8. ESR spectra recorded at $77 \mathrm{~K}$ for aqueous solutions of sephadex, dextran, melibiose, maltose, glucose, and xylose $\gamma$ irradiated at $77 \mathrm{~K}$ and annealed for $3 \mathrm{~min}$ at the temperature corresponding to the third relaxation region of polycrystalline matrix. Microwave power 100.3 and $0.1 \mathrm{~mW}$. 
and annealed at $200 \mathrm{~K}$ xylose (Fig. 7), are almost identical, $g_{1}=2.0055, \mathrm{~g}_{\|}=2.031$, and very close to those of ESR spectra for unambiguously identified peroxy radicals in other systems, $c f$. [18-22].

In the system under discussion the peroxy radicals formed at the temperatures corresponding to the beginning of the third relaxation region do decay within that region by elimination of hydroperoxy or superoxide radicals which [2-7], in turn, dismutate spontaneously [12].
[1] A. Płonka, J. Bednarek, and J. Kroh, Bull. Acad. Polon. Sci. Sér. Sci. Chim. 27, 79 (1979).

[2] G. O. Phillips, Radiation Res. 18, 446 (1963).

[3] S. Kawakishi, Y. Kito, and M. Namiki, Carbohydr. Res. 39, 263 (1975).

[4] M. N. Schuchmann and C. von Sonntag, Z. Naturforsch. $33 \mathrm{~b}, 329$ (1978).

[5] M. N. Schuchmann and C. von Sonntag, J. Chem. Soc. Perkin Trans. II 1977, 1958.

[6] A. G. W. Bradbury and C. von Sonntag, Z. Naturforsch. $31 \mathrm{~b}, 1274$ (1976).

[7] E. Bothe, D. Schulte-Frohlinde, and C. von Sonntag, J. Chem. Soc. Perkin Trans. II 1978, 416.

[8] V. A. Sharpatyi, M. T. Nadzhimiddinova, L. I. Kudryashov, and E. I. Bortsova, Khim. Vys. Energ. 2, 286 (1968).

[9] M. T. Nadzhimiddinova and V. A. Sharpatyi, Dokl. Akad. Nauk SSSR 180, 909 (1968).

[10] N. M. Emanuel, V. A. Sharpatyi, M. T. Nadzhimiddinova, L. I. Kudryashov, S. M. Yarovaya, and N. K. Kochetkov, Dokl. Akad. Nauk SSSR 177, 1142 (1967).

[11] L. I. Kudryashov, S. M. Yarovaya, E. I. Bortsova, and V. A. Sharpatyi, Zh. Obshch. Khim. 41, 2298 (1971).
[12] L. Kevan, Radiation Chemistry of Frozen Aqueous Solutions, in G. Stein (ed.): Radiation Chemistry of Aqueous Systems, Weizmann Science Press of Israel, Jerusalem 1968.

[13] G. P. Johari and S. I. Jones, J. Chem. Phys. 62, 4213 (1975).

[14] P. J. Baugh, K. Kershaw, and G. O. Philips, J. Chem. Soc. (B) 1970, 1482.

[15] I. E. Makarov, B. G. Ershov, and A. K. Pikaev, Proc. Tihany Symp. Radiat. Chem. 1971 (pub. 1972) 1181 .

[16] J. D. Zimbrick and L. S. Myers (Jr.), J. Chem. Phys. 54, 2899 (1971).

[17] V. A. Sharpatyi and M. N. Sultankhodzhaeva, Dokl. Phys. Chem. 208, 1157 (1973).

[18] P. J. Sullivan and W. S. Koski, J. Am. Chem. Soc. 85, 384 (1963).

[19] C. Chachaty and E. Hayon, J. Chim. Phys. 60, 1115 (1964).

[20] S. Lee and I. M. Brown, J. Magn. Reson. 22, 393 (1976).

[21] N. N. Tsomaya, A. D. Bichiashvili, and E. M. Nanobashvili, Izv. Akad. Nauk Gruz. SSSR, Ser. Khim. 1977, 437.

[22] E. S. Copeland, J. Magn. Reson. 20, 124 (1975). 